\title{
BEYOND CLINICAL CARE: THE PHARMACOECONOMIC AND RESEARCH ROLES OF PHARMACISTS IN POLAND
}

\author{
IGA PAWŁOWSKA ${ }^{1}$, NATALIA KRZYŻANIAK ${ }^{2}$, LESZEK PAWŁOWSKI ${ }^{3 *}$ \\ and IVAN KOCIĆ
}

${ }^{1}$ Chair and Department of Pharmacology, Medical University of Gdańsk, ul. Dębowa 23, Gdańsk 80-204, Poland

${ }^{2}$ University of Technology Sydney, Graduate School of Health (Pharmacy), Broadway, NSW, Sydney, Australia

${ }^{3}$ Department of Palliative Medicine, Medical University of Gdańsk, Dębinki 2, 80-211 Gdańsk, Poland

\begin{abstract}
The objective of the study was to identify pharmacoeconomic and research-based roles performed by pharmacists in Polish hospitals to provide an indication of the type of practice performed in these settings. Moreover, we would like to determine what pharmacotherapy-based cost-saving initiatives are undertaken by hospital pharmacists. We conducted a nationwide questionnaire survey among directors of hospital pharmacies from all general hospitals in Poland. For statistical analysis, Chi-squared Pearson's test was applied. 166 out of 273 directors of hospital pharmacies took part in this study (response rate of 60.8\%). Only 38/166 settings achieved sufficient founding form Polish public health insurance. To decrease costs of therapy hospital pharmacists take part in tenders (156/166), apply for drug donations (145/166) and purchase generic medicines (120/166). A small number of pharmacists perform both pharmacoeconomic (40/166) and scientific research (15/166). A high majority of hospital pharmacists take initiatives to decrease therapy costs. It is positive that pharmacists are involved in pharmacoeconomic duties, however, it is unknown to what degree these services may save limited measures. Overall, scientific research is not a common practice in Polish hospitals and it is still insufficient.
\end{abstract}

Keywords: hospital pharmacist, pharmacoeconomics, research, costs savings

According to the European Statements of Hospital Pharmacy, health systems resources, which are limited, should be used rationally to optimize outcomes for patients (1).

Pharmacotherapy is recognized as being the most highly used intervention in medical settings (2). Medicines are essential in not only curing diseases but also maintaining and improving quality of life (2). However, alongside these benefits, there are distinct challenges including medication error, sideeffects, adverse events etc (3). The most significant consequences of these challenges include patient morbidity, mortality as well as economic implications $(3,4)$. As a result, the role of the pharmacist extends beyond clinical parameters and also includes pharmacoeconomic considerations.

Pharmacoeconomics is the scientific discipline that evaluates the clinical, economic and humanistic aspects of pharmaceutical products, services and programmes (European Statements of Hospital
Pharmacy, glossary) (1). Thus, pharmacoeconomics refers to any simple activities aimed at cost-saving i.e. generic substitution. There is a significant amount of evidence from a global pool of literature that suggests pharmacist-initiated interventions have a positive influence on decreasing therapy costs (5, 3). An English article stated that 4-5\% of interventions made by pharmacists were related to costeffectiveness (5). The authors defined cost-effectiveness as an 'intervention made that allowed a less expensive medication regime to be prescribed without compromising patient care". Pharmacist recommendations in an Indian intensive care unit (ICU) over a period of 7 months rendered a total net saving of \$1797.73USD (3). Other literature highlights pharmacist roles impact upon costs associated with direct drug therapy, length of stay, changes to medical procedures or laboratory monitoring $(3,6)$.

Furthermore, pharmacists should play a key role in performing research related to hospital phar-

* Corresponding author: e-mail: lpawlowski@gumed.edu.pl 
macy practice (1). These studies may concern pharmacoeconomics, clinical aspects, pharmacotherapy, and others. Pharmacoeconomic research, in particular, relates to the analyses involving cost-effectiveness, pharmaceutical policy and drug use evaluation (7). The Australian Society of Hospital Pharmacists (SHPA) consider clinical research an essential pharmacist activity driven towards improving patientcentered care (8). This expanded scope of pharmacist responsibilities increases practice opportunities for pharmacists. However, it is unknown to what degree these roles are adapted in Poland, where pharmacist roles are depicted in literature as being primarily traditional i.e. dispensary based (9). Therefore, the aim of this study was to identify pharmacoeconomic and research-based roles performed by pharmacists in Polish hospitals to provide an indication of the type of practice performed in these settings. Moreover, we would like to determine what pharmacotherapy-based cost-saving initiatives are undertaken by hospital pharmacists.

\section{METHODS}

This is an exploratory study, seeking to identify the roles of hospital pharmacists in Polish general hospitals. An anonymous survey was sent out to the directors of pharmacy at every general hospital in Poland (273 according to the database of Health Care Institutions, accessed 2013). All setting categorized as 'general hospital' were included and the other health care institutions e.g. sanatoria, hospices were excluded. Specific details on the design, methodology and background characteristics of the hospitals and respondents as well as the questionnaire are presented in full in the previously published article (10).
This short report presents a sub-section of data obtained as part of the larger study, related to the pharmacoeconomic and research roles of pharmacists. For statistical analysis, descriptive statistics, and Chi-squared Pearson's test were applied. The former method was used to present the basic features of the data and the latter one was applied to find statistically significant correlations between obtained data.

\section{RESULTS}

Overall, a total of $166 / 273$ heads of hospital pharmacies responded to the surveys, with a response rate of $60.8 \%$.

\section{Pharmacist roles performed in polish hospitals to decrease the costs of therapy}

The most commonly reported roles performed by pharmacists to reduce costs of therapy included: taking part in tenders related to the purchase of medicines, requesting drug donations from pharmaceutical companies and the purchasing of generic medicines (Fig. 1).

It was found that pharmacies located in small cities (less than 100000 inhabitants) apply for more drug donations from pharmaceutical companies than those in larger cities ( $p=0.00063$; Chi ${ }^{-}$squared Pearson's test). Participation in clinical trials was also deemed a cost-saving activity and was undertaken more often in hospitals in bigger cities (0.00003, Chi-squared Pearson's test).

These pharmacoeconomic roles were deemed to be essential by pharmacists, as $42 \%(n=70)$ of hospitals surveyed highlighted that funding provided by the Polish public health insurance institution (National Health Fund, NFZ) only partially covered

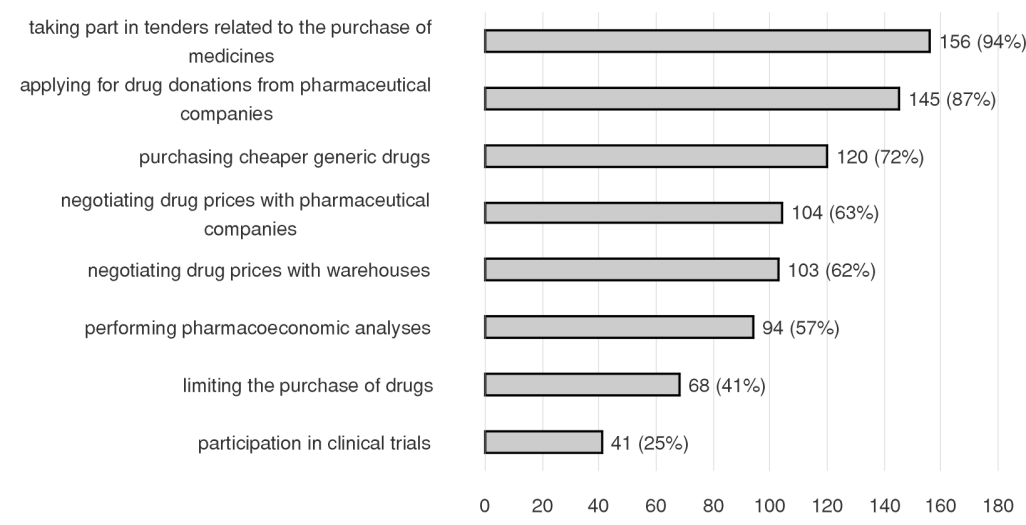

Figure. 1 Activities of the hospital leading to decrease the therapy costs. 
Table 1. Correlation between the activities of the hospital leading to decrease the therapy and the size of the city where the hospital is located.

\begin{tabular}{|c|c|c|c|}
\hline \multirow{2}{*}{$\begin{array}{c}\text { Activities of the hospital leading to } \\
\text { decrease the therapy costs: }\end{array}$} & \multicolumn{2}{|c|}{$\begin{array}{c}\text { Size of the city where the hospital is located } \\
(\mathrm{n}=163)\end{array}$} & $\begin{array}{c}\text { Chi } \\
\text { squared } \\
\text { Pearson's } \\
\text { test }\end{array}$ \\
\cline { 2 - 3 } & $\begin{array}{c}\text { less than 100 000 } \\
\text { inhabitants }(\mathrm{n}=108)\end{array}$ & $\begin{array}{c}\text { more than 100 000 } \\
\text { inhabitants (n = 55) }\end{array}$ & $\mathrm{p}=0.06990$ \\
\hline $\begin{array}{c}\text { Taking part in tenders related to the purchase } \\
\text { of medicines }\end{array}$ & $104(68.0 \%)$ & $49(32.0 \%)$ & $\mathrm{p}=0.00063$ \\
\hline $\begin{array}{c}\text { Applying for drug donations from } \\
\text { pharmaceutical companies }\end{array}$ & $101(71.1 \%)$ & $41(34.7 \%)$ & $\mathrm{p}=0.66085$ \\
\hline $\begin{array}{c}\text { Purchasing cheaper generic drugs } \\
\text { Negotiating drug prices with pharmaceutical } \\
\text { companies }\end{array}$ & $69(67.7 \%)$ & $33(32.3 \%)$ & $\mathrm{p}=0.62759$ \\
\hline Negotiating drug prices with warehouses & $68(66.7 \%)$ & $34(33.3 \%)$ & $\mathrm{p}=0.88644$ \\
\hline Performing pharmacoeconomic analyses & $60(65.2 \%)$ & $32(34.8 \%)$ & $\mathrm{p}=0.74916$ \\
\hline Limiting the purchase of drugs & $45(67.2 \%)$ & $22(32.8 \%)$ & $\mathrm{p}=0.83797$ \\
\hline Participation in clinical trials & $15(38.5 \%)$ & $24(61.5 \%)$ & $\mathrm{p}=0.00003$ \\
\hline
\end{tabular}

the hospitals needs relating to the procurement of essential medicines and medical devices needed by each facility. A further 5 participants highlighted that the NFZ did not cover these needs at all, whereas $23 \%(\mathrm{n}=38)$ of hospitals deemed the funding to be sufficient for their requirements. As such, hospitals are charged with decreasing the costs of therapy in order to maintain a consistent level of stock within budgetary constraints.

\section{Research based roles}

Approximately $24 \%$ of pharmacists $(n=40)$ claimed to be engaged in pharmacoeconomic research. According to participants, the studies comprised the following topics: drug utilization at the hospital, costs of antibiotics and their impact on the total drug budget, evaluations on the effectiveness of alternative methods of therapy and their associated costs, rationalization of pharmacotherapy, searching for the most economical and lowestpriced therapies (including generic drugs), cost minimalization analyses and other pharmacoeconomic analyses. In contrast, pharmacist participation in scientific research was identified at only $15(9 \%)$ hospital pharmacies. In general terms, the majority of these respondents identified these roles in clinical trials studies as involving: the provision of drugs for clinical research, stocking and evidencing the medicines and preparing individual patient doses.

\section{DISCUSSION}

To the best of our knowledge, this is the first study to have quantitatively identified what pharma- coeconomic and research roles are performed by hospital pharmacists in Poland. An important finding highlights that pharmacists are highly involved in cost-saving activities e.g. taking part in tenders, applying for drug donations, purchasing cheaper generic drugs and negotiating drug prices. K. Dalton and S. Byrne in their paper indicate other measures to decrease costs of the therapy such as: discontinuing unnecessary therapy, switching to less expensive agents, changing the route of administration, preventing ADEs and further healthcare utilization (11).

These roles are thought to be undertaken mainly due to the insufficient levels of funding being provided by public insurance NFZ for the purchase of drugs in most general hospitals. Additionally, the performance of these activities is also associated with the economic policies of hospitals and as a result, pharmacists require a good understanding of the rationalization of drug therapies. This is an interesting finding, as the majority of published literature highlights pharmacist impact on drug therapy costs from the perspective of appropriate clinical recommendations $(12,13,14)$. Pharmacist interventions relating to side effects, dosages, length of therapy, type of therapy, medication errors etc. have been shown to have an impact upon drug consumption, length of stay, the probability of readmission and/or laboratory monitoring, therefore decreasing expenditures (15). However, in this instance, pharmacists are heavily involved in the procurement of medicines, with a direct influence on expenditures. As such, it can be assumed that most hospital pharmacies in Poland operate on the system that the phar- 
macy department is responsible for purchasing and managing pharmaceutical stock, rather than utilizing a separate hospital department i.e. medical stores. However, it is unknown what degree of economic impact is felt when pharmacists are directly involved in the procurement of medicines. Moreover, there is a lot of evidence that pharmaceutical care is cost-effective - it improves outcomes of patient care with an only small increase in total costs $(16,17,18)$. In Poland, pharmacists work is mainly drug-oriented - only $10 \%$ of general hospitals declared to provide pharmaceutical care (10). Therefore, at the majority of Polish hospitals, this pharmaceutical service does not have any impact on decreasing costs of the therapy.

Economic analyses were listed by more than half of pharmacists as one of the main methods of cutting the costs of therapy. There is a discrepancy noted in the results relating to the performance of pharmacoeconomic analyses. Approximately 57\% of pharmacists identified that they performed these types of analyses to cut costs, but only $24 \%$ identified that they perform pharmacoeconomic research. These differences in percentages may be attributed to the interpretation of pharmacoeconomic research as data to be used for publications, conferences etc. whereas pharmacoeconomic analyses may be interpreted as being used for practical purposes within the hospital to highlight costs incurred etc.

Overall, it is apparent that scientific research is not common practice in Polish hospital pharmacies, with pharmacoeconomic studies being more prevalent. It is assumed that these studies are mainly performed for the internal needs of the hospital rather than for scientific purposes. It is important that pharmacists become more engaged in valid clinical research as they can play a fundamental role in the conduct and success of clinical trials. However, Barras highlights that there is a declining interest in pharmacist engagement in scientific research (8). Several barriers have been identified in the literature that limits pharmacist participation, including: lack of time, perceived lack of value associated participation in research and inaccessibility to experienced mentors $(8,19)$. These may apply to the situation in Poland, however, further investigation is required to determine why pharmacists are not more commonly involved in this type of research.

\section{CONCLUSIONS}

To sum up, Polish hospital pharmacists take initiatives to decrease the cost of the therapy, with the majority engaging in tenders for the purchase of medicines, cooperating with pharmaceutical companies and purchasing generic drugs.

In general, hospital pharmacists are involved in doing research to a small extent, however, pharmacoeconomic research was also found to be more commonly performed than other scientific research. It is positive that pharmacists are directly involved in pharmacoeconomic duties however it is unknown to what degree these services have a positive impact upon costs. Future research should be aimed at quantifying the impact of these roles in decreasing costs and highlighting the value of the pharmacist both from a financial and clinical aspect.

\section{REFERENCES}

1. European Statements on Hospital Pharmacy: Eur. J. Hosp. Pharm. 21, 256 (2014).

2. Bond C.: Pharm. J. 292, 509 (2014).

3. Lucca J.M., Ramesh M., Narahari G.M., Minaz N.: J. Pharmacol. Pharmacother. 3, 242 (2012).

4. Capsy A., Rozenfeld V., Kleyman J.: Prevention of medication errors in the hospital settings; The role of pharmacy students. Pharm. Ter. 30, 183 (2005).

5. Campbell G., Auyeung V., McRobbie D.: Int. J. Clin. Pharm. 35, 688 (2013).

6. Saokaew S., Maphanta S., Thangsomboon P.: Pharm. Pract. (Granada) 7, 81 (2009).

7. Grizzle A.: Health Outcomes \& Pharmaco Economic Research. The Univeristy of Arizona. http://www.pharmacy.arizona.edu/centers/healt h-outcomes-pharmacoeconomic-research, 2016 (accessed: 14. 12. 2016).

8. Barras M.: AJP 96, 30 (2015).

9. Pawłowska I., Kocić I.. Eur. J. Hosp. Pharm. 21, 372 (2014).

10. Pawłowska I., Pawłowski L., Kocić I., Krzyżaniak N.: Int. J. Clin. Pharm. 38, 271 (2016).

11. Dalton K., Byrne S.: Integr. Pharm. Res. Pract. 6, 37 (2017).

12. Jourdan J.P., Muzard A., Goyer I., Ollivier Y., Oulkhouir Y. et al.: Int. J. Clin. Pharm. 40, 1474 (2018)

13. Han J.M., Ah Y.M., Suh S.Y., Jung S.H., Hahn H.J. et al.: Int. J. Clin. Pharm. 38, 1124 (2016).

14. Gallagher J., McCarthy S., Byrne S.: Int. J. Clin. Pharm. 36, 1101 (2014).

15. Sawyer R.T., Odom J.M., Jennings J., Orr J., Cass A.L.: GHS Proc. 1, 32 (2016).

16. Obreli-Neto P.R., Marusic S., Guidoni C.M., Baldoni Ade O., Renovato R.D. et al.: J. Manag. Care. Spec. Pharm. 21, 66 (2015). 
17. Yu J., Shah B.M., Ip E.J., Chan J.: J. Manag. Care Pharm. 19, 102 (2013).

18. Altavela J.L., Jones M.K., Ritter M.: J. Manag. Care Pharm. 14, 831 (2008).
19. Cvijovic K., Boon H., Jaeger W., Vohra S.: Int. J. Pharm. Pract. 18, 377 (2010).

Received: 10.09. 2018 